\title{
вмJ Global Health From direct engagement to technical support: a programmatic evolution to improve large community health worker programs in Bihar, India
}

\author{
Jess Wilhelm, ${ }^{1}$ Tanmay Mahapatra, ${ }^{2}$ Aritra Das (D) ,,3 Sunil Sonthalia, ${ }^{2}$ \\ Sridhar Srikantiah, ${ }^{2}$ Christine Galavotti, ${ }^{3}$ Hemant Shah, ${ }^{2}$ Andreea A Creanga
}

To cite: Wilhelm J, Mahapatra T, Das A, et al. From direct engagement to technical support: a programmatic evolution to improve large community health worker programs in Bihar India. BMJ Global Health 2021;6:e004389. doi:10.1136/ bmjgh-2020-004389

Handling editor Seye Abimbola

- Additional supplemental material is published online only. To view, please visit the journal online (http://dx.doi.org/10. 1136/bmjgh-2020-004389).

Received 5 November 2020 Revised 2 March 2021 Accepted 20 March 2021

Check for updates

(c) Author(s) (or their employer(s)) 2022. Re-use permitted under CC BY. Published by BMJ.

${ }^{1}$ Department of International Health, Johns Hopkins University Bloomberg School of Public Health, Baltimore, Maryland USA

${ }^{2}$ CARE India Solutions for Sustainable Development, Patna, Bihar, India ${ }^{3}$ CARE USA, Atlanta, Georgia USA

Correspondence to Dr Andreea A Creanga; acreang3@jhu.edu

\section{ABSTRACT}

Introduction In 2011, through a multipartner Integrated Family Health Initiative (IFHI), CARE started supporting maternal and neonatal health (MNH) improvement goals in 8 of 38 districts in Bihar, India. The programme included a frontline health worker (FHW) component offering health advice through household visits and benefited from CARE's direct engagement during IFHI, which then evolved into statewide Technical Support Unit (TSU) to the Government of Bihar in 2014.

Methods Using eight rounds of state-representative household surveys with mothers of infants aged $0-2$ months ( $N=73093$ ) linked with two facility assessments conducted during 2012-2017, we assessed changes in FHW visit coverage, intensity and quality between IFHI and TSU phases. Using logistic regression models, we ascertained associations between FHW outputs and three MNH core practices: $\geq 3$ antenatal care check-ups (ANC3+), institutional delivery and early breastfeeding initiation.

Results Women's receipt of 1+ FHW visits declined from $60.2 \%$ (IFHI phase) to $46.3 \%$ (TSU phase) in the eight IFHI districts, being below $40 \%$ statewide during the TSU phase. Despite a parallel decline in FHW visit quality measured as the number of health advice received, all three outcomes improved during the TSU versus IFHI phase in IFHI districts. We found significant positive associations between all three outcomes and receipt of 1+ FHW visits and programme phase (TSU vs IFHI) in the eight IFHI districts. During the TSU phase, receipt of 2+ FHW visits in the third trimester increased the odds of women receiving ANC3+ $($ adjusted OR $(\mathrm{aOR})=1.21 ; 95 \% \mathrm{Cl}: 1.13$ to 1.31), delivering in a facility $(\mathrm{aOR}=1.64 ; 95 \% \mathrm{Cl}$ : 1.51 to 1.77 ) and initiating breast feeding early $(\mathrm{a} 0 \mathrm{R}=1.18 ; 95 \% \mathrm{Cl}: 1.05$ to 1.18). Independent of the number and timing of FHW visits, we also found positive associations between women reporting higher than lower quality of FHW interactions and receiving outcome-specific advice and all three MNH outcomes. Conclusion Implementation of large communitybased interventions under the technical support model should be continuously and strategically evaluated and adapted.

\section{WHAT IS ALREADY KNOWN?}

$\Rightarrow$ Programmes with community-based components can accelerate improvements in maternal and neonatal health (MNH) in low-resource countries.

$\Rightarrow$ In recent years, frontline health worker (FHW) programmes provided household visits and provision of health advice to pregnant and postpartum women and infants in Bihar with support from development partners, which included CARE.

$\Rightarrow$ The initial, eight-district phase (Integrated Family Health Initiative, IFHI) that started in 2011 and benefited from CARE's direct engagement evolved into a Technical Support Unit (TSU) phase in 2014.

\section{WHAT ARE THE NEW FINDINGS?}

$\Rightarrow$ The coverage, intensity and quality of FHW services were greater during the IFHI than the TSU phase.

$\Rightarrow$ During the TSU phase, receipt of $2+$ FHW visits in the third trimester increased the odds of women receiving $\geq 3$ antenatal care check-ups, delivering in a facility and initiating breast feeding early.

$\Rightarrow$ Independent of the number and timing of FHW visits, we also found positive associations between women reporting higher than lower quality of FHW interactions and receiving outcome-specific advice and all three MNH outcomes.

\section{WHAT DO THE NEW FINDINGS IMPLY?}

$\Rightarrow$ Given continuous improvements in $\mathrm{MNH}$ outcomes in Bihar, implementation of large community-based interventions under the TSU model should be continuously and strategically evaluated and adapted.

\section{INTRODUCTION}

Community-based interventions have long been considered important components of comprehensive approaches to accelerate improvements in reproductive, maternal, newborn and child health and nutrition (RMNCHN) outcomes in low/middleincome countries (LMICs). They promote appropriate care seeking and improved home practices mainly through home-based 
counselling or participatory women's groups. ${ }^{12}$ The evidence regarding the effectiveness of community-based interventions on improving such practices is strong for interventions focusing on health education, promotion of antenatal care (ANC), safe delivery with skilled birth attendants and support of exclusive breast feeding of infants. ${ }^{3-5} \mathrm{By}$ and large, programmes that combine community-based and facility-based interventions are found to be more effective, suggesting a potential benefit of holistic approaches. ${ }^{45}$ The successful implementation of such programmes is expected to depend on context, ${ }^{3}$ thus questions remain regarding where, when and how to scale up promising interventions with a communitybased component.

Walt $e t a t^{6}$ were among the first to document common challengeswith large-scalecommunity-based programmes, including unrealistic expectations, poor initial planning, difficulties in ensuring consistency in programme quality and funding. Among commonly credited enabling factors noted by Pallas et al were programmes' management structure, the inclusion of strong training and supervision components, and the integration and support from within health systems. Conversely, key barriers identified were programmes' weak management, supervision and monitoring, coupled with inadequate incentives to retain and motivate community health workers. Smith $e t a l^{8}$ put forth principles for successfully scaling up health interventions. Key among these were developing mechanisms to promote local ownership and building institutional capacity at all levels during implementation. In line with these principles, in recent years, we have witnessed how implementation of large health programmes placed increasing emphasis on providing technical support for programme managers, key stakeholders and governments aimed at strengthening the entire health system rather than directly engaging in specific programme activities. ${ }^{910}$ This technical support model for managers of community-based programmes is expected to channel support to community health workers despite competing programme objectives and limited resources, flexibility and capacity of non-governmental implementing partners. As noted by Chambers et al, ${ }^{11}$ over time, this model may lead either to a 'voltage drop' or to sustainable scale-up of pilot programmes if adequately adapted to the local context.

With a population of over 1.3 billion people, India accounts for $12 \%$ of maternal deaths ${ }^{12}$ and $35 \%$ of neonatal deaths worldwide. ${ }^{13}$ In 2005, the Government of India launched the National Rural Health Mission (NRHM) to strengthen provision of community health services and increase equity and affordability of care in rural areas. ${ }^{14}$ Interventions implemented under the NRHM included staffing, training, and equipping referral facilities and deploying community-based cadres, referred to as frontline health workers (FHWs), to promote institutional deliveries, particularly in low-performing Indian states. ${ }^{15-18}$ FHW cadres include accredited social health activists (ASHAs) and Anganwadi workers (AWWs) who have a minimum of 8 and 10 years of education, respectively, as well as auxiliary nurse midwives (ANMs) who are trained nurses. Under the NRHM, the Janani Suraksha Yojana (JSY) initiative provides 1400 Indian rupees to eligible women who deliver in health facilities as well as incentives for the ASHAs in the communities where these women reside for accompanying them to the facility or for facilitating institutional birth. ${ }^{19}$ With NRHM funding, large numbers of health workers, including doctors, staff nurses, ANMs and ASHAs were contracted during 2005-2014 in low-performing Indian states. Bihar, the third most populous state where $>34 \%$ of the population lived below the poverty line,$^{20}$ was one of them. The state has seen significant improvements in health indicators in recent years, such as the rise in institutional deliveries from $19.9 \%$ in $2005-2006$ to $63.8 \%$ in $2015-2016,{ }^{21}$ but FHW mobilisation to promote health services at the community level was particularly poor in Bihar. ${ }^{22}$

CARE India is a non-profit organisation and a lead partner in a multiorganisational platform aiming to improve RMNCHN in Bihar. ${ }^{23}$ In 2011, CARE launched the Integrated Family Health Initiative (IFHI) in eight programmatically prioritised districts of Bihar covering 28 million people to support the Government of Bihar $(\mathrm{GoB})$ in increasing the coverage and quality of life-saving interventions for women, newborns and children. ${ }^{23}$ Programme support for IFHI involved direct engagement with programme activities by CARE (table 1). In close collaboration with the GoB, CARE and other partners participated in planning, coordination and logistical support; capacity building; behaviour change communications; work with women's self-help groups (SHGs) and health system strengthening. For community-level interventions, CARE employed an incremental learning approach, involving FHWs through the existing 2550 health subcentre platforms. The main IFHI hypothesis was that an increase in the level and quality of efforts on the part of FHWs would result in improved service coverage in facilities as well as improvements in healthcare practices and behaviours at the family level. A close connect to the family in the last trimester of pregnancy was strongly emphasised as critical to a range of outcomes for the mother and baby. The IFHI phase generated convincing evidence to take interventions to scale. ${ }^{23}$

During 2014, in close coordination with GoB, the programme evolved into a Technical Support Unit (TSU) and was rolled out in all 38 districts of Bihar covering over 104 million people. This phase was characterised by a considerable reduction in direct engagement in programme activities by CARE, yet deeper focus on capacity building, strengthening the supervisory system, synergising and focusing efforts on select interventions (eg, nurse mentoring and training), ${ }^{24}$ and using monitoring data. As a result, CARE acted as a catalyst to facilitate provision of necessary technical, managerial and resource optimisation support at critical levels of programme implementation, while building community and government ownership of the programme. With 
Table 1 Intervention phases in Bihar, India

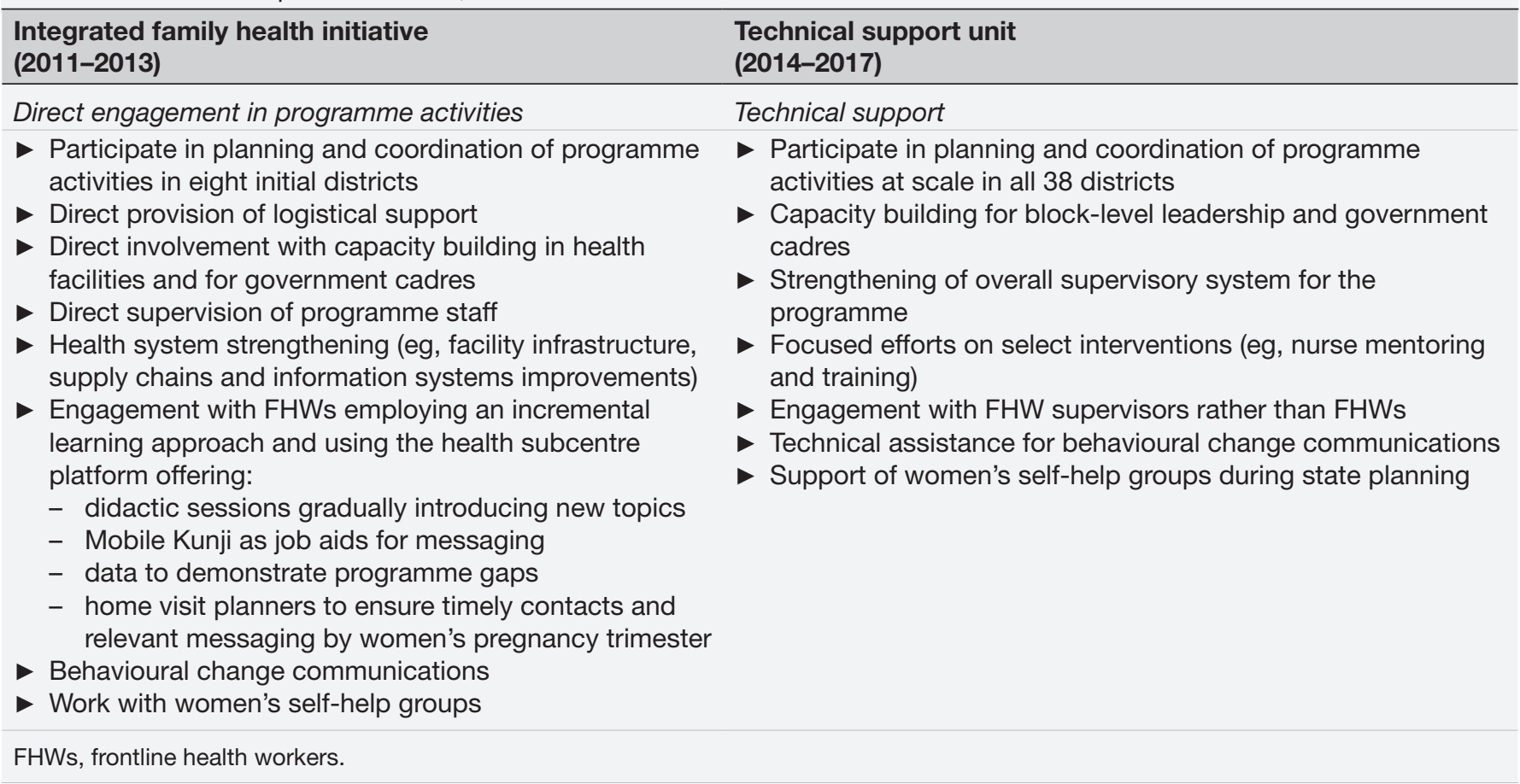

regard to the FHWs, the shift from IFHI to TSU can be characterised as a shift from relatively greater direct engagement to relatively greater technical support.

This analysis focuses on the FHW component of the programme in Bihar during 2011-2017. We aimed to: (1) assess and compare the coverage, intensity, and quality of FHWs' interactions with pregnant women during household visits during IFHI (eight districts) and TSU (statewide) phases, and (2) ascertain and compare associations between FHW programme outputs and the uptake of three core maternal and neonatal health (MNH) programme practices: $\geq 3$ ANC check-ups (ANC3+), institutional delivery and early $(<1$ hour of birth) breastfeeding initiation. Of note, early initiation of breast feeding was a key programme target in Bihar during both IFHI and TSU phases; ANC and institutional delivery became specific programme targets only in 2015 and 2016, respectively, after the programme started to benefit from a multidimensional quality improvement initiative implemented in all public health facilities in the state between 2014 and $2017 .^{24}$

\section{METHODS}

\section{Patient and public involvement}

Women and their families were not directly involved in setting the research questions or the outcome measures for the programme or this specific analysis of programme data. However, these were developed in consultation with and guidance from community leaders, and women and their families were intimately involved in the design and implementation of the programme in Bihar. Through community sensitisation meetings, they received information about the programme and its goals, which in turn helped motivate their participation in household surveys. We intend to disseminate the main results of this analysis to the community in Bihar through CARE India colleagues who continue to be engaged in the programme to serve the community.

\section{Data}

We used eight rounds of household surveys conducted by CARE with mothers of infants 0-2 months old in Bihar. Four survey rounds (P1-P4) were conducted about 6 months apart during the IFHI phase (2012-2013) in all 137 blocks in eight districts using lot quality assurance sampling methodology; the total P1-P4 sample was 10408 mothers (online supplemental table 1). Systematic random samples of mothers, 1 from each of 19 randomly selected Anganwadi Center (AWC) areas in each block, were recruited for interviews; weights were derived using the number of births in each block to generate rural population-based estimates of intervention coverage and outcomes of interest. Four household survey rounds (S1S4) were conducted statewide annually during the TSU phase (2014-2017) using a two-stage stratified sampling methodology covering all 534 blocks in all 38 districts; the total S1-S4 sample was 62685 mothers. Within each block, the AWC list from GoB's Integrated Child Development Scheme was used as sampling frame, being considered the most comprehensive and up-to-date list. ${ }^{25}$ Samples were distributed across different blocks to obtain a minimum sample size of 388 mothers per district and 19 mothers per block. The number of AWCs selected in each block was determined based on the proportional 
contribution of each block's population to the respective district population, aiming to sample one household with infants 0-2 months old in each selected AWC. Within each AWC, the household list compiled by the local AWW was used to randomly select an index household in the community. The index household was not sampled, and enumerators proceeded to the fifth household from the index in a clockwise fashion to identify resident mothers of infants 0-2 months old who had delivered more than 7 days before. If the first fifth household did not have an eligible mother present, the enumerator continued to the following fifth household until an eligible mother was identified for interview. Block-level survey weights were generated to account for the complex survey design and were used in our analyses. Verbal informed consent was obtained from eligible women who agreed to complete the interviews. District-level response rates varied between $96 \%$ and $98 \%$ across survey rounds.

Survey questionnaires collected information on women's sociodemographic characteristics, obstetric history, JSY programme participation, interactions with FHWs and the types of health advice received from them during and after pregnancy, receipt of ANC and delivery care as well as neonatal care practices. While some variation between survey questionnaires existed for P1-P4 vs S1-S4 surveys, for this analysis, we selected questions that were consistently asked across survey rounds to derive FHW and outcome indicators of interest.

\section{Analyses}

We generated FHW programme output variables: a binary (yes/no) indicator to identify women who received $1+$ FHW visits during pregnancy; a four-category variable derived from three survey questions ('At any time during the pregnancy, did (ASHA/AWW/ANM) ever come to your home to talk to you about your or your expected baby's health?', 'Was it a health-related visit?', and 'How many visits did you receive from FHWs during the third trimester of pregnancy?') and categorised as: received no FHW visits during pregnancy, received 1+ FHW visit(s) but not in the last trimester of pregnancy, received only 1 FHW visit during the last trimester of pregnancy, and received 2+ FHW visits during the last trimester of pregnancy; indicators capturing specific types of FHW advice (ie, danger signs, institutional delivery, delivery with a skilled birth attendant, safe delivery practices, early breast feeding, skin-to-skin care, family planning); and an index of the quality of interactions with FHWs derived from questions regarding advice received across five domains: birth preparedness for institutional delivery, birth preparedness for home delivery, recognition and care seeking for maternal complications, essential newborn care practices and postpartum family planning. This quality index accounts for the number of domains of advice received (0-5 range). For ease of interpretation, in the analysis, we used a binary FHW interaction quality variable categorised as 'high quality' if the index is $\geq 4$ (90th percentile of index score) and 'average or lower quality' if the index is $<4$.

We explored trends in several outcomes: ANC (any, 3+, $4+$ check-ups); institutional delivery; presence of skilled birth attendant for home deliveries; skin-to-skin practice right after birth; early initiation of breast feeding, defined as breast feeding initiated $<1$ hour after birth and estimated only among women with a vaginal delivery; and newborn weighing. For the analysis of FHW visits' effects, we selected three outcomes based on their relevance in the $\mathrm{MNH}$ field and the availability of strong evidence around community-based interventions' success on improving these outcomes ${ }^{45}$ : ANC3+, institutional delivery and early initiation of breast feeding. A fourth outcome, television ownership, was chosen as 'falsification test ${ }^{26}$ to assess potential confounding in the associations of interest between FHW outputs and outcomes. We suspected that latent factors, such as women's willingness to adopt new behaviours, may result in both more efficient interactions with FHWs and improved outcomes. But, it is unlikely that household visits and provision of health advice by FHWs would lead to a television purchase, selected over other types of purchases because of its lower prevalence than other household items (eg, radio) in Bihar and because it is purely a consumption good, unlike vehicles or gas stoves.

We identified potential confounders of the associations of interest. Sociodemographic factors included maternal age, parity, religion, caste, mother's and husband's education and literacy, tertiles of a household wealth index generated as time-varying price-weighted sum of 25 household items (P1-P4) and 27 items (S1-S4) assessed in each survey round. Contextual factors included: JSY programme participation (yes/no) available in all survey rounds, and SHG membership (yes/no) only available in S1-S4. Facility-level factors in block-level facilities where the woman resided were obtained from two rounds of comprehensive facility assessments conducted in 2015 (linked with P1-P4 and S1 data) and 2016 (linked with S2-S4 data). They included the level of block-level facility (lowest level considered if more than one facility per block as most likely first source of care), and the ratio of clinical staff (doctors, nurses, nurse-midwives) filled to that approved in the block-level facility.

For our first study objective, we first examined trends in FHW programme outputs by survey round and inclusion in the IFHI phase, and trends in outcomes by survey round and place of delivery (ie, home, public or private facility) when applicable. Multivariable logistic regression models were fitted for each of the outcomes using only the data from the eight IFHI districts comparing the TSU with the IFHI phase. Models were adjusted for women's receipt of 1+ FHW visits, an interaction term between programme phase and receipt of 1+ FHW visits, and the potential confounders listed above; the model fitted for early breastfeeding initiation was also adjusted for whether the woman delivered in a facility or not. Models were estimated using generalised estimating equations 
to account for clustering of facility-level covariate data. In regression analyses, we controlled for all potential confounders noted above.

For the second study objective, we fitted a second set of four multivariable logistic regression models using only the TSU phase (S1-S4) data. Models were adjusted for the FHW household visit frequency, the quality of interactions with FHWs, the provision of outcome-specific advice as well as the potential confounders listed above. Compared with the first set of regression models, these models were adjusted for SHG membership and IFHI district status. Models were estimated using generalised estimating equations to account for clustering of facilitylevel covariate data. Using this second set of regression models, we estimated the predicted marginal probabilities of the outcomes under a variety of hypothetical scenarios to illustrate the relative impact of FHW visit frequency, quality of interactions and provision of outcome-specific advice compared with the impact of changes in other factors known to influence MNH outcomes: female literacy, SHG membership and delivery in a health facility.

All analyses were conducted in Stata V.15 and accounted for the complex survey design using Taylor's linearisation method. Data can be made available upon request and under a data use agreement with CARE, India.

\section{RESULTS}

About three in four women in our samples were 20-29 years old and had two or three children (table 2). The majority of women were Hindu and belonged to the nonmarginalised caste. Among women interviewed during the IFHI phase, $36.4 \%$ were literate; this percentage was higher $(44.6 \%)$ for women interviewed during the TSU phase.

\section{Coverage of FHW interactions with pregnant women}

In the eight IFHI districts, the coverage of pregnant women with 1+ FHW visits during pregnancy peaked at $65.0 \%$ in round $\mathrm{P} 4$ at the end of the IFHI phase but declined during the TSU phase to about $40 \%(\mathrm{p}<0.001)$; this level of coverage was above that in the 30 non-IFHI districts, which was stagnant at $<40 \%$ until the end of 2017 (table 3, online supplemental table 2). Coverage of 2+ visits during third trimester of pregnancy declined even more dramatically from $60.2 \%$ in round $\mathrm{P} 4$ to $24.1 \%$ in round $\mathrm{S} 4(\mathrm{p}<0.001)$ in the eight IFHI districts, being at $<30 \%$ in the 30 non-IFHI districts in rounds S2-S4. Trends in FHWs offering specific types of advice, including advice regarding institutional delivery and early breastfeeding initiation, followed similar patterns. The quality of interactions with FHWs during household visits also declined significantly $(\mathrm{p}<0.001)$ from an average index score of 3.3 domains of advice covered by FHWs at the end of the IFHI phase (P4) to around 2 domains of advice covered in the eight IFHI districts during the TSU phase (online supplemental figure 1). Declines in advice related to home birth preparedness, maternal complications and related care seeking, and postpartum family planning appear to be driving this trend.

\section{Changes in MNH outcomes during the programme}

Despite declines in FHW outputs, we found a significant increase in ANC3+ between the time of the S1 survey and the period captured by S2-S4 surveys, more so among the non-IFHI than IFHI districts $(\mathrm{p}<0.001$; online supplemental table 3). Institutional deliveries remained about constant over time, with a slight increase noted at the time of the S4 survey and levels being overall higher among IFHI than non-IFHI districts during the TSU phase. Early initiation of breast feeding increased in the IFHI districts throughout the initial phase, reached a peak at the time of the $S 2$ survey $(\mathrm{p}<0.001)$, to decline afterwards as captured in S3 and S4 surveys; levels for this outcome indicator were slightly lower in non-IFHI than IFHI districts throughout the TSU phase.

\section{Changes in FHW programme outputs and MNH outcomes between programme phases}

We compared FHW programme outputs, MNH outcomes, and contextual measures between the IFHI and the TSU phase in the eight IFHI districts, and between the 8 IFHI vs 30 non-IFHI districts during the TSU phase. While, on average, $53.4 \%$ of pregnant women in the eight IFHI districts received 2+ FHW visits during the third trimester of pregnancy during the IFHI phase, the proportion declined to $31.2 \%$ during the TSU phase $(\mathrm{p}<0.001)$; only $26.6 \%$ of pregnant women received such visits in the 30 non-IFHI districts during the TSU phase (table 3). Of women who received a FHW visit, the proportion with high-quality FHW interactions (ie, quality index $\geq 4$ domains of advice) declined from $43.4 \%$ (IFHI phase average) to $21.9 \%$ (TSU phase average) in the eight IFHI districts $(\mathrm{p}<0.001)$, and was $18.2 \%$ (TSU phase average) in the 30 non-IFHI districts. Coverage of specific advice for institutional delivery declined from $46.9 \%$ to $36.9 \%$ $(p<0.001)$ in the eight IFHI districts between the IFHI and TSU phases, being $31.4 \%$ for the 30 non-IFHI districts during the TSU phase. The decline in coverage of FHW visits with advice for early breastfeeding initiation was even more pronounced dropping from an average of $41.2 \%-22.9 \%$ in the eight IFHI districts between the IFHI and TSU phases, being $16.1 \%$, on average, in the 30 nonIFHI districts during the TSU phase. Despite declining coverage and quality of FHW interactions, outcomes improved during the TSU phase compared with the IFHI phase $(22.3 \%-40.9 \%$ for ANC3+, $72.6 \%-75.6 \%$ for institutional delivery, and $57.1 \%-70.1 \%$ for early breastfeeding initiation) in the eight IFHI districts. Also, participation in the JSY programme declined considerably between the initial (38.7\%) and the TSU (12.4\%) phase in the eight IFHI districts, being $14 \%$ statewide during the TSU phase $(\mathrm{p}<0.001)$. Membership in SHG was $15.5 \%$ statewide during the TSU phase. 
Table 2 Population characteristics by programme phase: Bihar, 2011-2017

\begin{tabular}{|c|c|c|c|c|}
\hline \multirow[b]{2}{*}{ Characteristics } & \multicolumn{2}{|c|}{$\begin{array}{l}\text { Initial } \\
\text { eight programme districts }\end{array}$} & \multirow{2}{*}{$\begin{array}{l}\text { Additional } \\
30 \text { districts } \\
\text { TSU }\end{array}$} & \multirow{2}{*}{$\begin{array}{l}\text { All } \\
38 \text { districts } \\
\text { TSU } \\
\end{array}$} \\
\hline & IFHI & TSU & & \\
\hline $\mathrm{N}$ & 10408 & 13767 & 48918 & 62685 \\
\hline \multicolumn{5}{|l|}{ Age (years; \%) } \\
\hline$<20$ & 6.0 & 11.3 & 9.7 & 10.1 \\
\hline $20-24$ & 42.9 & 45.5 & 46.3 & 46.1 \\
\hline $25-29$ & 33.4 & 29.8 & 30.4 & 30.2 \\
\hline $30-34$ & 12.8 & 9.8 & 9.8 & 9.9 \\
\hline $35+$ & 5.0 & 3.7 & 3.9 & 3.9 \\
\hline Mean (SE; years) & $24.9(0.5)$ & $24.1(0.4)$ & $24.3(0.2)$ & $24.2(0.2)$ \\
\hline \multicolumn{5}{|l|}{ Religion (\%) } \\
\hline Hindu & 86.5 & 86.0 & 83.2 & 84.1 \\
\hline Other* & 13.5 & 14.0 & 16.8 & 15.9 \\
\hline \multicolumn{5}{|l|}{ Caste $(\%)$} \\
\hline Marginalised (Scheduled Caste/Tribe) & 26.8 & 24.7 & 27.7 & 27.0 \\
\hline Non-marginalised & 73.2 & 75.3 & 72.3 & 73.0 \\
\hline \multicolumn{5}{|l|}{ Household wealth index $†$} \\
\hline Lowest tertile & 34.0 & 31.0 & 34.3 & 33.4 \\
\hline Middle tertile & 33.2 & 36.1 & 33.4 & 34.1 \\
\hline Highest tertile & 32.8 & 32.8 & 32.3 & 32.5 \\
\hline Knows to read and write (\%) & 36.4 & 43.6 & 45.0 & 44.6 \\
\hline \multicolumn{5}{|l|}{ Education (completed years; \%) } \\
\hline No formal education & 63.6 & 56.7 & 55.8 & 56.1 \\
\hline $1-8$ & 21.3 & 21.3 & 19.5 & 20.0 \\
\hline$>8$ & 15.1 & 21.9 & 24.7 & 24.0 \\
\hline Husband knows to read and write (\%) & 58.5 & 60.5 & 60.2 & 60.2 \\
\hline \multicolumn{5}{|l|}{ Husband's education (completed years; \%) } \\
\hline No formal education & 42.9 & 44.2 & 43.8 & 43.9 \\
\hline $1-8$ & 31.0 & 27.2 & 23.4 & 24. \\
\hline$>8$ & 26.0 & 28.6 & 32.8 & 31.7 \\
\hline Mean (SE) number of living children & $2.8(0.2)$ & $2.8(0.2)$ & $2.7(0.1)$ & $2.7(0.1)$ \\
\hline Mean (SE) age of last born at the time of interview (days) & $42(0.3)$ & $47(0.3)$ & $47(0.1)$ & $47(0.1)$ \\
\hline
\end{tabular}

All data are weighted.

*Includes Muslim, Christian, other religion.

†Household wealth index generated as time-varying price-weighted sum of 25 (IFHI phase) or 27 (scale-up phase) household items assessed.

IFHI, Integrated Family Health Initiative; TSU, Technical Support Unit.

\section{Associations between FHW visits and MNH outcomes in the initial eight districts by programme phase}

After adjustment for potential confounders, we found significant positive associations between the three MNH outcomes (ANC3+, institutional delivery and early initiation of breast feeding) and receipt of 1+ FHW visits and programme phase (TSU vs IFHI) in IFHI districts (table 4). Delivery in a facility increased the odds of initiating breast feeding early (adjusted OR $(\mathrm{aOR})=2.24$, 95\% CI: 2.10 to 2.40 ). Women's and their husbands' literacy were positively associated with attendance of ANC3+ check-ups and institutional delivery, but not with early initiation of breast feeding. Women of higher parity and those belonging to marginalised than nonmarginalised caste had lower odds of attending ANC3+ check-ups and delivering in a facility, but higher odds of initiating breast feeding early. Having a higher level facility than only a primary health centre in the block was associated with higher odds of having ANC3+ check-ups, while higher filled-to-approved clinical staffing ratios 
Table 3 Summary of contextual, output and outcome measures by programme phase: Bihar, 2011-2017

\begin{tabular}{|c|c|c|c|c|}
\hline \multirow[b]{2}{*}{ Measures } & \multicolumn{2}{|c|}{$\begin{array}{l}\text { Initial } \\
\text { eight programme districts }\end{array}$} & \multirow{2}{*}{$\begin{array}{l}\text { Additional } \\
30 \text { districts } \\
\text { TSU }\end{array}$} & \multirow{2}{*}{$\begin{array}{l}\text { All } \\
38 \text { districts } \\
\text { TSU }\end{array}$} \\
\hline & IFHI & TSU & & \\
\hline $\mathrm{N}$ & 10408 & 13767 & 48918 & 62685 \\
\hline \multicolumn{5}{|l|}{ Contextual } \\
\hline JSY programme participation (\%) & 38.7 & 12.4 & 14.6 & 14.0 \\
\hline Self-help group membership (\%) & $\mathrm{n} / \mathrm{a}$ & 15.6 & 15.4 & 15.5 \\
\hline \multicolumn{5}{|l|}{ FHW programme outputs } \\
\hline \multicolumn{5}{|l|}{ FHW household visit frequency (\%) } \\
\hline No visit during pregnancy & 39.8 & 53.7 & 61.5 & 59.3 \\
\hline Only visits in 1st or 2nd pregnancy trimester & 1.3 & 6.8 & 4.9 & 5.4 \\
\hline Only one visit during 3rd pregnancy trimester & 5.5 & 8.4 & 7.0 & 7.4 \\
\hline $2+$ visits during 3rd pregnancy trimester & 53.4 & 31.2 & 26.6 & 27.8 \\
\hline \multicolumn{5}{|l|}{ Specific advice (\%) } \\
\hline Advice for institutional delivery & 46.9 & 36.9 & 31.4 & 32.9 \\
\hline Advice for early initiation of breast feeding & 41.2 & 22.9 & 16.1 & 18.0 \\
\hline \multicolumn{5}{|c|}{ Quality of FHW interactions during household visits† (\%) } \\
\hline Received advice on $4+$ domains & 43.4 & 21.9 & 18.2 & 19.4 \\
\hline \multicolumn{5}{|l|}{ Outcomes for this analysis } \\
\hline Attended 3+ ANC visits (\%) & 22.3 & 40.9 & 43.2 & 42.6 \\
\hline Institutional delivery (\%) & 72.6 & 75.6 & 70.9 & 72.2 \\
\hline Early initiation of breast feeding $\left.{ }^{*} \%\right)$ & 57.1 & 70.1 & 66.2 & 67.2 \\
\hline TV ownership (\%) & 12.4 & 15.6 & 17.5 & 17.0 \\
\hline
\end{tabular}

All data are weighted.

The index accounts for the number of domains of advice received across five domains: birth preparedness for institutional delivery, birth preparedness for home delivery (whether planned or unplanned), recognition and care seeking for maternal complications, essential newborn care practices and postpartum family planning. The index ranges between 0 and 5 .

*Early initiation of breast feeding refers to initiation within the first hour after birth and is only measured among women who had a vaginal delivery.

†The quality index was estimated among mothers of infants aged 0-2 months old who received one or more FHW visits during pregnancy. ANC, antenatal care; FHW, frontline health worker; IFHI, Integrated Family Health Initiative; JSY, Janani Suraksha Yojana; n/a, not available;

TSU, Technical Support Unit.

were associated with higher odds of ANC3+ check-ups and institutional delivery.

\section{Associations between FHW visits and MNH outcomes in all 38 districts during the TSU phase}

During the TSU phase, compared with women in the 30 non-IFHI districts, those in the eight IFHI districts had higher odds of delivering in a health facility $(\mathrm{aOR}=1.23$; 95\% CI: 1.09 to 1.38 ), yet lower odds of having ANC3+ check-ups $(\mathrm{aOR}=0.84 ; 95 \%$ CI: 0.76 to 0.93 ; table 4$)$. Also during the TSU phase, receipt of $2+$ FHW visits in the third trimester increased the odds of women receiving ANC3+ $(\mathrm{aOR}=1.21 ; 95 \% \mathrm{CI}: 1.13$ to 1.31$)$, delivering in a facility $(\mathrm{aOR}=1.64 ; 95 \% \mathrm{CI}: 1.51$ to 1.77$)$ and initiating breast feeding early (aOR=1.18; 95\% CI: 1.05 to 1.18$)$. Importantly, independent of the number and timing of FHW visits received, we found positive associations between women reporting a higher quality of interactions with FHWs and all ANC3+, institutional delivery and early initiation of breast feeding; in addition, receipt of outcome-specific advice (eg, to deliver in a facility) increased the odds of all three $\mathrm{MNH}$ outcomes, especially early breastfeeding initiation. Interestingly, SHG membership was positively associated with institutional delivery and early initiation of breast feeding, but not ANC3+. Associations between sociodemographic characteristics and all ANC3+, institutional delivery and early initiation of breast feeding were of similar magnitude and significance in models fitted for all 38 districts during the scale-up period as for the pooled initial and scale-up data from the eight IFHI districts. During the TSU phase, having a higher level than only a primary health centre in the block was associated with higher odds of women obtaining ANC3+ check-ups and delivering in a facility, but lower odds of early initiation of breast feeding. 


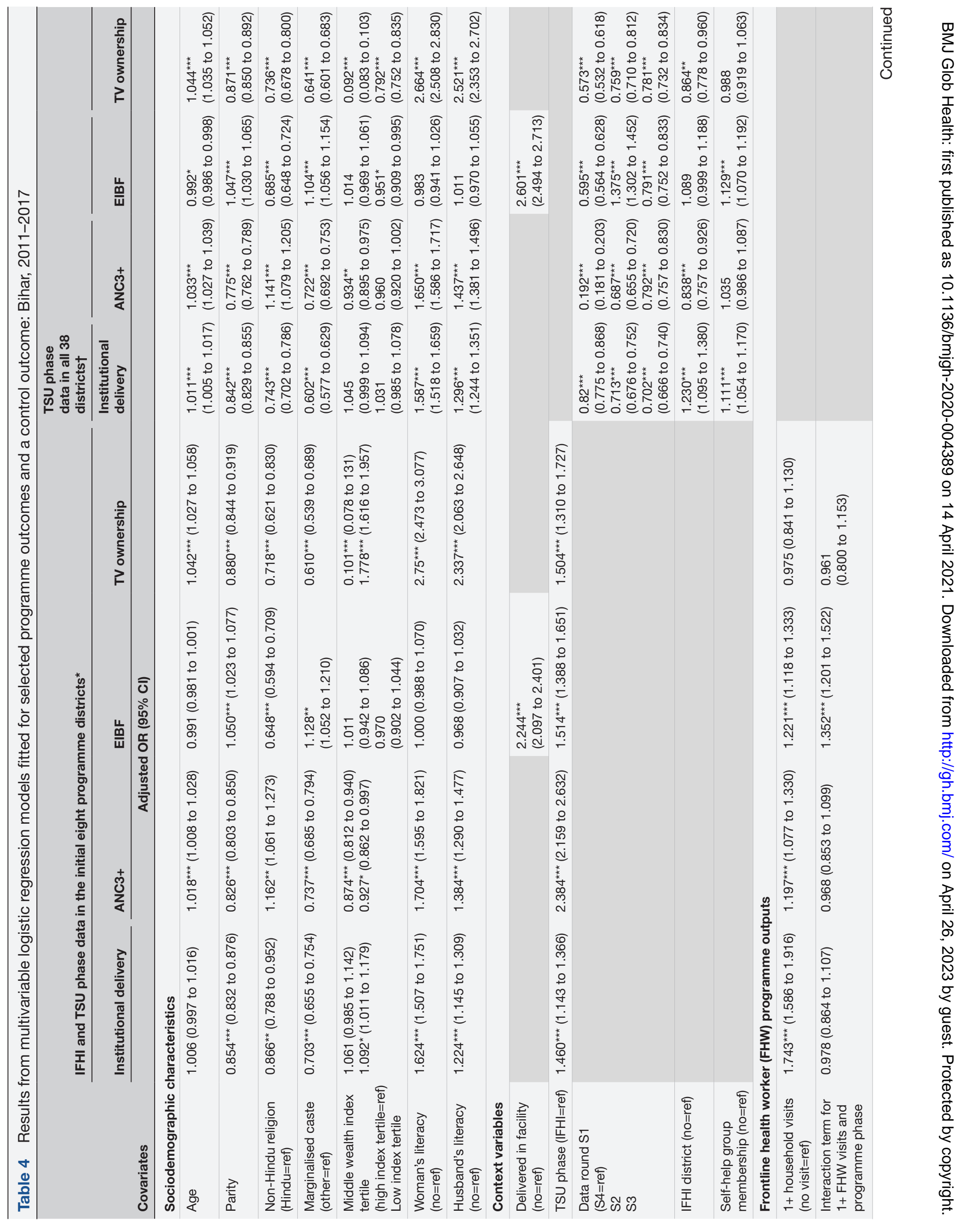




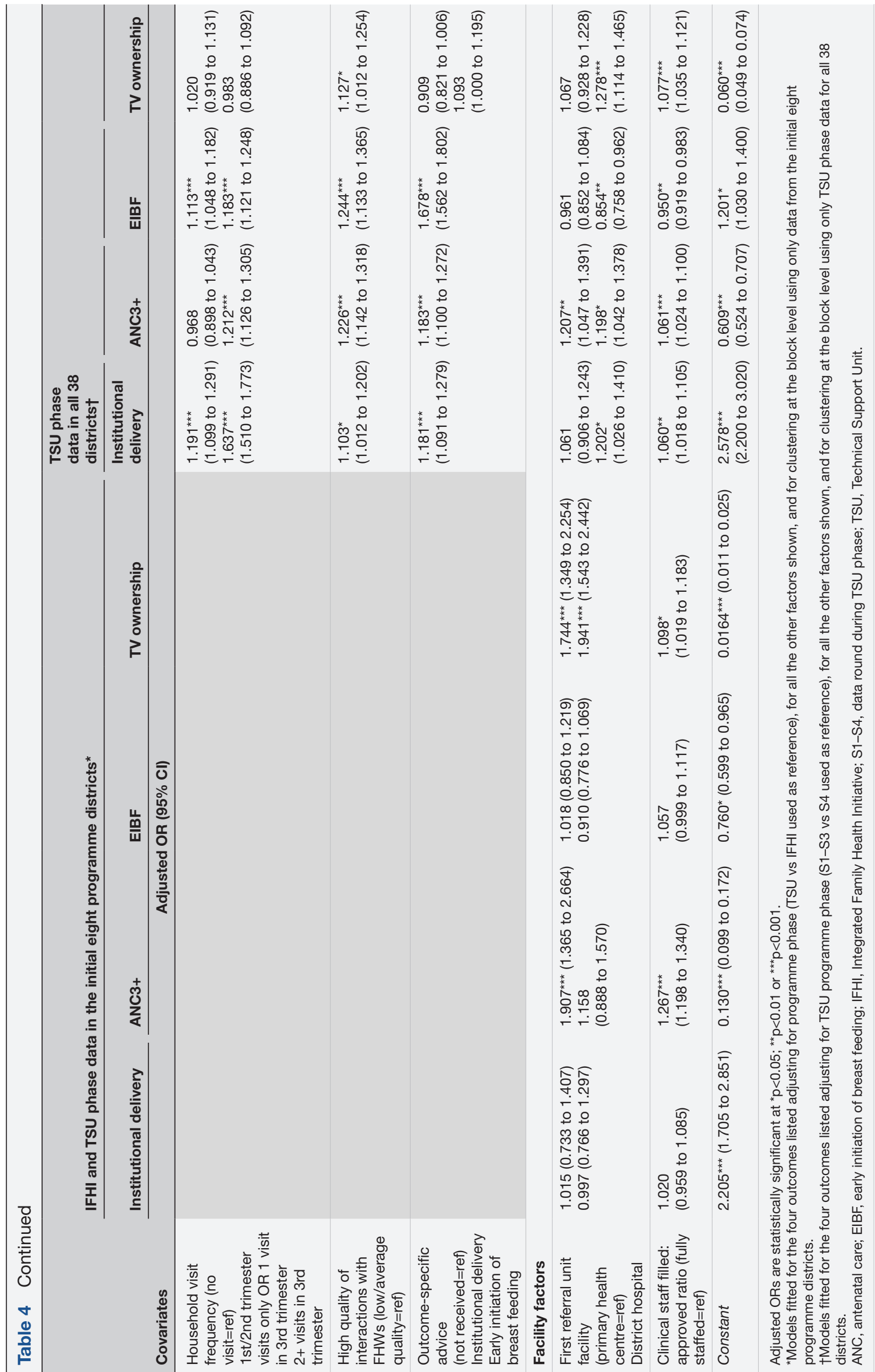




\section{Changes in MNH outcomes under hypothetical FHW or other programme scenarios}

Based on observed variable associations at the state level during the TSU phase, if all women would receive 2+ FHW visits in the third trimester of pregnancy with high-quality interactions and outcome-specific advice, the percentage of women with ANC3+ check-ups would increase from $41.7 \%$ to $48.5 \%$, that of women delivering in health facilities from $73.5 \%$ to $82.2 \%$, and that of women initiating breast feeding early from $67.5 \%$ to $81.9 \%$ (table 5 ). This scenario would lead to higher percentage point increases in coverage of all ANC3+, institutional delivery and early initiation of breast feeding than the estimated effects of achieving $100 \%$ maternal literacy rate or having all mothers in Bihar become members of SHGs.

\section{DISCUSSION}

Our findings indicate that the IFHI model of intense programming and direct engagement in programme activities by CARE did not sustain its impact on FHW service coverage and interaction quality during the subsequent, less intensive, but scaled-up model of technical support in Bihar. This erosion of impact is neither surprising nor overwhelming as positive changes were indeed observed in $\mathrm{MNH}$ outcomes during the TSU phase above and beyond secular trends. Importantly, these outcomes were positively associated with higher quality and outcome-targeted interactions between FHWs and pregnant women in the community. Taken together, our findings in Bihar mirror the experience with other large-scale programmes in LMICs where scaling up using a 'technical support' model also faced challenges, despite overall positive changes in programme outcomes. ${ }^{27-30}$ To place our findings in the broader Indian context, a systematic review of research published between 2005 and 2016 examining India's FHW programmes found that most articles had mixed results and only a few indicated overall positive findings. ${ }^{31}$

There are known reasons for which the technical support model faced challenges in achieving sustainable scale-up of the FHW programme component in Bihar. Well recognised among these, the GoB encountered difficulties in supporting AWWs during 2014-2016, ${ }^{32}$ but was then able to even increase their payment in $2017 .^{33}$ However, a recent study conducted in four Indian states showed that ASHAs' visits to beneficiaries were not more strongly associated with outcomes for which they were paid than outcomes for which they were unpaid. ${ }^{34}$ The Home Based Newborn Care initiative, rolled out in Bihar after 2014, provided incentives to ASHAs for postnatal follow-up visits and tracking of low birthweight newborns. ${ }^{35}$ The increased emphasis on postnatal care, while important, might have also affected the time ASHAs had for household visits to pregnant women. FHWs' performance was found to reflect the quality of their training, the time lapse since their last training, the intensity of mentoring and supervision they receive, and their work motivation. ${ }^{36}{ }^{37}$ Supervision appears to influence FHWs' motivation in India, with government than non-governmental organisation supervisors being less effective in motivating FHWs. ${ }^{36}$

ANC became a programme target in Bihar only in 2015. Nonetheless, we found positive, although modest associations between all 2+ FHW visits, the quality of FHW interactions and receipt of ANC-specific advice from FHWs on women having ANC3+ check-ups. Analyses of Indian Human Development Survey data showed that exposure to ASHA services was associated with a $17 \%$ and $5 \%$ increase in women attending 1 and $4+$ ANC visits, respectively. ${ }^{38}$ However, research in several Indian states found ANC services provided by ASHA workers were not adequate. ${ }^{39}$ In our study, women's literacy and affiliation with SHGs was found to be positively associated with ANC attendance, likely through increased awareness, selfefficacy or perception of ANC as social norm. These findings have likely been influenced by the improvements in public facilities through the facility-based component of the programme over time. Another notable factor behind the rising ANC3+ trend might be the village health, sanitation and nutrition days (VHSND) platform, which made ANC interventions available to large numbers of pregnant women within the community.

Institutional deliveries increased considerably in Bihar as the JSY programme expanded during 2011-2012. With delayed payments and changes from distributing cash to making bank deposits, the proportion of mothers reporting receiving JSY programme incentives declined from $46 \%$ (P4 data) to 6\% (S3 data) - the trend in institutional deliveries remained flat during this time as the programme in Bihar also prioritised improving quality of care in public facilities rather than reaching a higher institutional delivery target (online supplemental figure 2). Following an increase in JSY participation and the programme focusing on such in 2017 (S4 data), the proportion of institutional deliveries increased again. These data suggest that delivery in a health facility is closer to becoming the norm in Bihar despite changes with the JSY programme, and the FHWs appear to have played an important role in this positive trend. Women's literacy also appears to be an important driver for institutional delivery, a result of the focus placed on girls' education in the early 2000s. ${ }^{40}$ Others found similar associations between exposure to FHWs and institutional deliveries in India. ${ }^{34} 384142$

Visits by FHWs have plausibly driven the increasing proportion of women initiating breast feeding earlythey appear to, both directly and indirectly through institutional delivery, influence early breastfeeding practices. Only $18.0 \%$ (statewide TSU phase average) of pregnant women received advice from FHWs to start breast feeding early, a level that is comparable with that reported in the evaluation of a similar programme in Uttar Pradesh. ${ }^{43}$ We found that if all women received 2+ FHW visits in the third trimester that are of high quality and include advice for early breast feeding, the predicted coverage of early 


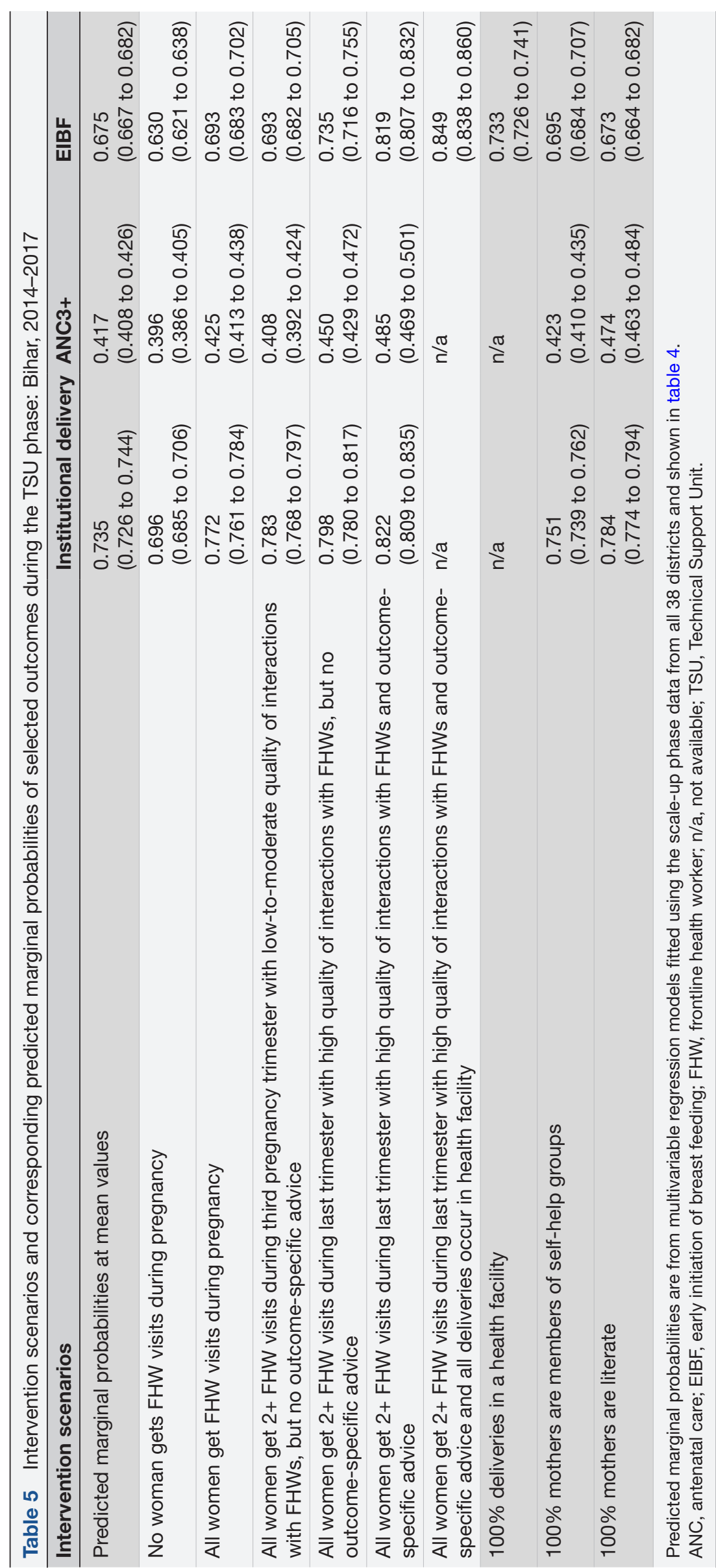


breast feeding would increase from $67.5 \%$ to $81.9 \%$, or even to $84.9 \%$ if all deliveries would also occur in health facilities.

This study has several limitations. We rely on crosssectional household survey data and cannot infer causality in observed associations. The sample frame for these surveys is limited to areas served by AWCs, thus, possibly, excluding some limited areas in the state. Women's self-reported information in surveys is subject to social desirability and recall bias-the former would bias our associations upwards by causing women with more exposure to FHW advice to over-report positive behaviours; the latter would only affect our findings if differential, making associations of interest appear stronger. As the case with most studies, there is risk for residual confounding. Programme components that may have played a role in the observed associations, such as massmedia education campaigns, interactions with FHWs and other health providers during immunisation campaigns and VHSND, were not measured in household surveys in Bihar. Of note, our 'falsification test' worked well and gives confidence in our results-the only significant association between our control outcome (ie, TV ownership) and FHW exposure relates to the quality of interactions with FHWs, which can be explained by women being receptive to various channels of information. Importantly, given the tautological nature of the relationship between JSY programme participation and institutional deliveries in India, it is difficult to assess the true contribution of the FHW programme to changes in institutional deliveries during the period of study. A sensitivity analysis that adjusted our facility delivery models for JSY participation showed a significant effect of this programme on women delivering in a facility (online supplemental table 4).

\section{CONCLUSION}

Implementation of FHW interventions should be continuously and strategically evaluated and adapted in Bihar. Attention should be given to addressing potential barriers to obtaining sustainable impact at scale, including weak leadership and supervision, limited implementation management capacity and variable engagement, competition between programme components, variation in implementation fidelity and FHW motivation. The relative costs and benefits of supporting FHW programmes alone or in tandem with other strategies to improve $\mathrm{MNH}$ outcomes should be considered. Adoption of a stepwise approach to FHW programme scale-up and integration into the health system and a thorough preparedness prior to transitioning to a technical support model for implementing and maintaining programmes at scale appear to be key to achieving positive and sustainable results. ${ }^{10} 44$

Acknowledgements We thank the members of the Bihar Technical Support Program of CARE India and of the Department of Health \& Family Welfare, Government of Bihar for implementing this work and sharing their views on programme implementation and its success with the authors.
Contributors JW, AAC, TM and AD contributed to the conception and design and drafting of the manuscript; all authors revised it critically for important intellectual content and approved the final manuscript.

Funding The study was financially supported by a grant from the Bill and Melinda Gates Foundation (Grant ID\# OPP1016872CARE).

Disclaimer The funding source was not involved in the design of this study.

Competing interests None declared.

Patient consent for publication Not required.

Ethics approval The Institutional Committee for Ethics and Review of Research of the Indian Institute of Health Management Research in Jaipur, India approved data collection activities undertaken by CARE during 2014-2015. The Ashirwad Ethics Committee at the Ashirwad Hospital and Research Center in Ulhasnagar, India did so for data collection activities in 2016 and subsequently.

Provenance and peer review Not commissioned; externally peer reviewed.

Data availability statement Data are available upon request. Data can be made available upon request and under a data use agreement with CARE, India.

Supplemental material This content has been supplied by the author(s). It has not been vetted by BMJ Publishing Group Limited (BMJ) and may not have been peer-reviewed. Any opinions or recommendations discussed are solely those of the author(s) and are not endorsed by BMJ. BMJ disclaims all liability and responsibility arising from any reliance placed on the content. Where the content includes any translated material, BMJ does not warrant the accuracy and reliability of the translations (including but not limited to local regulations, clinical guidelines, terminology, drug names and drug dosages), and is not responsible for any error and/or omissions arising from translation and adaptation or otherwise.

Open access This is an open access article distributed in accordance with the Creative Commons Attribution 4.0 Unported (CC BY 4.0) license, which permits others to copy, redistribute, remix, transform and build upon this work for any purpose, provided the original work is properly cited, a link to the licence is given, and indication of whether changes were made. See: https://creativecommons.org/ licenses/by/4.0/.

\section{ORCID iDs}

Aritra Das http://orcid.org/0000-0002-7033-1441

Andreea A Creanga http://orcid.org/0000-0001-5171-006X

\section{REFERENCES}

1 Hanson C, Kujala S, Waiswa P, et al. Community-Based approaches for neonatal survival: meta-analyses of randomized trial data. Bull World Health Organ 2017;95:453-64.

2 Prost A, Colbourn T, Seward N, et al. Women's groups practising participatory learning and action to improve maternal and newborn health in low-resource settings: a systematic review and metaanalysis. Lancet 2013;381:1736-46.

3 Perry HB, Rassekh BM, Gupta S, et al. Comprehensive review of the evidence regarding the effectiveness of community-based primary health care in improving maternal, neonatal and child health: 1. rationale, methods and database description. $J$ Glob Health 2017;7:010901

4 Jennings MC, Pradhan S, Schleiff M, et al. Comprehensive review of the evidence regarding the effectiveness of community-based primary health care in improving maternal, neonatal and child health: 2. maternal health findings. J Glob Health 2017;7:010902.

5 Sacks E, Freeman PA, Sakyi K, et al. Comprehensive review of the evidence regarding the effectiveness of community-based primary health care in improving maternal, neonatal and child health: 3. neonatal health findings. J Glob Health 2017;7:010903.

6 Walt G, Ross D, Gilson L, et al. Community health workers in national programmes: the case of the family welfare educators of Botswana. Trans R Soc Trop Med Hyg 1989;83:49-55.

7 Pallas SW, Minhas D, Pérez-Escamilla R, et al. Community health workers in low- and middle-income countries: what do we know about scaling up and sustainability? Am J Public Health 2013;103:e74-82.

8 Smith ER, Hurt L, Chowdhury R, et al. Delayed breastfeeding initiation and infant survival: a systematic review and meta-analysis. PLoS One 2017;12:e0180722.

9 Bennett S, Singh S, Rodriguez D, et al. Transitioning a large scale HIV/AIDS prevention program to local stakeholders: findings from the Avahan transition evaluation. PLoS One 2015;10:e0136177. 
10 Ozawa S, Singh S, Singh K, et al. The Avahan transition: effects of transition readiness on program institutionalization and sustained outcomes. PLoS One 2016;11:e0158659.

11 Chambers DA, Glasgow RE, Stange KC. The dynamic sustainability framework: addressing the paradox of sustainment amid ongoing change. Implement Sci 2013;8:117.

12 WHO, UNICEF, UNFOA. World bank group and the United nations population division: trends in maternal mortality 2000 to 2017: estimates by who, UNICEF, UNFPA, world bank group and the United nations population division. Geneva: World Health Organization, 2019. https://www.who.int/reproductivehealth/ publications/maternal-mortality-2000-2017/en

13 Liu L, Oza S, Hogan D, et al. Global, regional, and national causes of under-5 mortality in 2000-15: an updated systematic analysis with implications for the sustainable development goals. Lancet 2016;388:3027-35.

14 Dongre AR, Deshmukh PR, Garg BS. A community based approach to improve health care seeking for newborn danger signs in rural Wardha, India. Indian J Pediatr 2009;76:45-50.

15 Gupta SK, Pal DK, Tiwari R, et al. Impact of Janani Suraksha Yojana on institutional delivery rate and maternal morbidity and mortality: an observational study in India. J Health Popul Nutr 2012;30:464-71.

16 Shah P, Shah S, Kutty RV, et al. Changing epidemiology of maternal mortality in rural India: time to reset strategies for MDG-5. Trop Med Int Health 2014;19:568-75.

17 Goudar SS, Derman RJ, Honnungar NV, et al. An intervention to enhance obstetric and newborn care in India: a cluster RandomizedTrial. Matern Child Health J 2015;19:2698-706.

18 Government of India. Ministry of health and family welfare. National health mission overview, 2013. Available: http://nhm.gov.in/nrhmcomponents/rmnch-a/maternal-health/janani-suraksha-yojana/ background.html [Accessed 3 Nov 2020].

19 UNFPA - India. Concurrent assessment of Janani Suraksha Yojana (JSY) in selected states, 2009. Available: http://india.unfpa.org/sites/ default/files/pub-pdf/JSYConcurrentAssessment.pdf [Accessed 3 Nov 2020].

20 Central statistical office, government of India. Handbook of Indian statistics, 2017. Available: https://www.rbi.org.in/Scripts/ PublicationsView.aspx?id=17634 [Accessed 3 Nov 2020].

21 Ministry of Health and Family Welfare. Bihar state fact sheet 20152016. Mumbai: International Institute for Population Sciences. Available: http://rchiips.org/nfhs/pdf/NFHS4/BR_FactSheet.pdf [Accessed 3 Nov 2020].

22 Kosec K, Avula R, Holtemeyer B, et al. Predictors of essential health and nutrition service delivery in Bihar, India: results from household and frontline worker surveys. Glob Health Sci Pract 2015;3:255-73.

23 CARE. Project brief: ensuring quality, rights-based family planning in Bihar, India. care, 2015. Available: http://familyplanning.care2share. wikispaces.net/file/view/BiharFPBrief2015_FINAL.pdf/567483345/ BiharFPBrief2015_FINAL.pdf [Accessed 3 Nov 2020].

24 Das A, Nawal D, Singh MK, et al. Evaluation of the mobile nurse training (MNT) intervention - a step towards improvement in intrapartum practices in Bihar, India. BMC Pregnancy Childbirth 2017;17:266

25 Rao N, Kaul V. India's integrated child development services scheme: challenges for scaling up. Child Care Health Dev 2018;44:31-40.

26 Prasad V, Jena AB. Prespecified falsification end points: can they validate true observational associations? JAMA 2013;309:241-2.

27 Bryce J, Victora CG, Habicht J-P, et al. Programmatic pathways to child survival: results of a multi-country evaluation of integrated management of childhood illness. Health Policy Plan 2005;20 Suppl $1: i 5-17$.
28 Bryce J, Gilroy K, Jones G, et al. The accelerated child survival and development programme in West Africa: a retrospective evaluation. Lancet 2010;375:572-82.

29 Huicho L, Dávila M, Campos M, et al. Scaling up integrated management of childhood illness to the National level: achievements and challenges in Peru. Health Policy Plan 2005;20:14-24.

30 Hazel E, Bryce J. On bathwater, babies, and designing programs for impact: evaluations of the integrated community case management strategy in Burkina Faso, Ethiopia, and Malawi. Am J Trop Med Hyg 2016;94:568-70.

31 Scott K, George AS, Ved RR. Taking stock of 10 years of published research on the ASHA programme: examining India's national community health worker programme from a health systems perspective. Health Res Policy Syst 2019;17:29.

32 India Pay Commission. Salary of Anganwadi ICDs, 2016. Available: https://www.7thpaycommissioninfo.in/salary-of-anganwadi-after/ [Accessed 3 Nov 2020].

33 United News of India. Government enhances Asha workers salary to RS 6000 per month, 2017. Available: http://www.uniindia.com/govtenhances-asha-workers-salary-to-rs-6000-per-month/states/news/ 862191.html [Accessed 3 Nov 2020].

34 Koehn HJ, Zheng S, Houser RF, et al. Remuneration systems of community health workers in India and promoted maternal health outcomes: a cross-sectional study. BMC Health Serv Res 2020;20:48

35 Government of India. Ministry of health and family welfare. home based newborn care. operational guidelines, 2011. Available: http://www.nihfw.org/pdf/NCHRC-Publications/Operational\% 20Guidelines\%20on\%20Home\%20Based\%20Newborn\%20Care\% 20(HBNC).pdf [Accessed 3 Nov 2020].

36 Wahid SS, Munar W, Das S, et al. 'Our village is dependent on us. That's why we can't leave our work'. Characterizing mechanisms of motivation to perform among Accredited Social Health Activists (ASHA) in Bihar. Health Policy Plan 2020;35:58-66.

37 Bhanderi DJ, Varun AR, Sharma DB. Evaluation of accredited social health activists in Anand district of Gujarat. J Family Med Prim Care 2018;7:571-6.

38 Agarwal S, Curtis SL, Angeles G, et al. The impact of India's accredited social health activist (ASHA) program on the utilization of maternity services: a nationally representative longitudinal modelling study. Hum Resour Health 2019;17:68.

39 Chaurasiya SK, Singh NP, Shukla SK, et al. Assessment of the services of ASHA workers on antenatal and postnatal care in a district of Western Uttar Pradesh, India. J Family Med Prim Care 2020;9:3502-7.

40 Bhattacharjee K. Women's Education in Rural Bihar: Issues and Challenges, 2018. Available: https://www.researchgate.net/ publication/318080118_Women's_Education_in_Rural_Bihar_Issues_ and_Challenges/references [Accessed 3 Nov 2020].

41 Paul PL, Pandey S. Factors influencing institutional delivery and the role of accredited social health activist (ASHA): a secondary analysis of India human development survey 2012. BMC Pregnancy Childbirth 2020;20:445.

42 Agarwal S, Curtis S, Angeles G, et al. Are community health workers effective in retaining women in the maternity care continuum? Evidence from India. BMJ Glob Health 2019;4:e001557.

43 Singh V, Ahmed S, Dreyfuss ML, et al. Non-governmental organization facilitation of a community-based nutrition and health program: effect on program exposure and associated infant feeding practices in rural India. PLoS One 2017;12:e0183316.

44 Zulu JM, Kinsman J, Michelo C, et al. Integrating national community-based health worker programmes into health systems: a systematic review identifying lessons learned from low-and middleincome countries. BMC Public Health 2014;14:987. 